\title{
O DILEMAS DAS REDES E A MODULAÇÃO DOS COMPORTAMENTOS DOS USUÁRIOS: O QUE ISSO TEM A VER COM OS PROCESSOS DE APRENDIZAGEM?
}

\section{THE NETWORK DILEMMAS AND THE MODULATION OF USER BEHAVIORS: WHAT DOES IT HAVE TO DO WITH LEARNING PROCESSES?}

\author{
Denize Sepulveda ${ }^{10}$ \\ Yuri Sepulveda ${ }^{11}$
}

\begin{abstract}
Resumo
Este artigo tem por finalidade estabelecer algumas análises sobre o documentário " $\mathrm{O}$ Dilema das Redes" e a sua relação com as modulações dos comportamentos dos usuários da internet. Defendemos que nessa troca se estabelecem processos de aprendizagens que interferem nas visões de mundo das pessoas, influenciando a conscientização crítica dos sujeitos. Nossas considerações provisórias apontam para a importância do papel da escola com es ${ }^{1213}$ estudantes, no que se refere à criação dos
\end{abstract}

10 Coordenadora adjunta e professora do Programa de Pós-Graduação em Educação (PPGedu) da Uerj/FFP. Professora adjunta da Universidade do Rio de Janeiro no Departamento de Educação - FFP. Pósdoutora pelo Programa de Pós-Graduação em Educação da UFF (2020). Pós-doutora pelo Programa de Pós-Graduação em Educação da Uerj/ PROPED (2016). Doutora pelo Programa de Pós-Graduação em Educação da UERJ (2012). Possui mestrado em Educação pela Universidade Federal Fluminense (2003). É bacharel e licenciada em História (1993). Sublíder do Grupo de Estudos e Pesquisa Conservadorismo e a Educação Brasileira (GEPCEB) da UFF. Coordenadora do Grupo de Pesquisa Gênero, Sexualidades e Diferenças nos Vários EspaçosTempos Cotidianos (GESDI) da Uerj/FFP. E-mail: denizesepulveda@hotmail.com. ORCID: https://orcid.org/0000-0001-9049-5200.

${ }_{11}$ Doutorando em Estudos Culturais na Universidade de Lisboa, na Faculdade de Letras. Mestre em Estudos Cinematográficos pela Universidade Lusófona de Humanidades e Tecnologias (2017). Graduado em Comunicação Social com habilitação em Cinema. Tem experiência na área de Comunicação, com ênfase em Comunicação Visual. Membro do Grupo de Estudos e Pesquisa Conservadorismo e a Educação Brasileira (GEPCEB) da UFF. E-mail: yurisepulveda1@hotmail.com. ORCID: https://orcid.org/0000-00018317-1662.

12 O uso do " $x$ " não é apenas uma forma de adaptação morfema-grafema. O " $x$ " é a negação da genitalização dos sujeitos e das palavras. Um resgate histórico pelo direito a não sexuação dos seres, como fora negado às pessoas intersexos ao longo da história. Logo, se existe uma incapacidade do leitor em ler essas agonísticas (POCAHY, 2018) no campo estético e político, o que deve ser melhorado é a tecnologia que permite a leitura e não a luta de um determinado grupo em detrimento a outro. 0 " $x$ ", enquanto quiasmo, refere-se ao encontro apical de duas retas que eclodem criando sentidos a outras formas negadas de uma desinência de gênero e suas compreensões (YORK, 2020).

${ }^{13}$ Nota das Editoras: visando dar acesso às pessoas com algum tipo de deficiência visual e disléxicos, bem como em respeito aos autores e suas militâncias, publicaremos outra versão, acessível aos ledores digitais. Esperamos que em breve essa limitação sociotecnológica seja superada. 


\title{
RevistAleph
}

espaços de emancipação, para que possam tecer maneiras de enfrentamentos diante de situações opressoras vivenciadas por jovens em redes sociais.

Palavras-chave: Redes Sociais. Comportamentos. Aprendizagem.

\begin{abstract}
This article aims to establish some analysis regarding the documentary " o dilema das redes" and its relation with the modulation of Internet user's behavior. We defend that in this relation a learning process is established in which interferes in people's worldview, influencing the subject critical awareness. Our provisory considerations point to the importance of the school rule along with the students as a means of creating spaces of emancipation, in order to elaborate ways of confronting toward oppressive situations experienced by teenagers in social networks.
\end{abstract}

Keywords: Social networks. Behaviors. Learning.

\section{Introdução}

O documentário norte-americano "O Dilema das Redes" foi dirigido por Jeff Orlowski e escrito por Davis Coombe, Vickie Curtis, além do próprio Orlowski. Foi lançado pela Netflix ${ }^{14}$ em 9 de setembro de 2020. O filme tem como objetivo discutir o papel das redes sociais e os malefícios que elas causam à sociedade como um todo, dando destaque à manipulação e à modulação que essas redes produzem nos comportamentos das pessoas, tendo como alvo aumentar o lucro das empresas que as gerenciam.

Por meio de uma linguagem extremamente moderna, o documentário vai se construindo através de uma narrativa que faz uso também da ficção. Ou seja, conforme es especialistas entrevistades falam sobre como as redes interferem na vida das pessoas, o filme nos apresenta uma família fictícia vivendo as questões que estão sendo levantadas pela narrativa fílmica. Essa mistura de documentário com ficção ajuda es

\footnotetext{
${ }^{14}$ Netflix é uma provedora global de filmes e séries de televisão com sede na Califórnia que, atualmente, possui em torno de 160 milhões de assinantes. Foi fundada em 1997, nos Estados Unidos. Inicialmente atuava como uma empresa de entrega de DVD pelo correio (https://canaltech.com.br/empresa/netflix/).
} 


\section{RevistAleph}

espectadores a vivenciarem catarses, a entrar na atmosfera criada pelo filme e, com isso, entender a problemática abordada. Entende-se por catarse o que Aristóteles descreveu na relação do indivíduo com as sensações causadas pela arte especificamente poesia e música. O cinema incorporou essa ideia para expressar o fato de que conseguimos, enquanto espectadores, nos relacionar emocionalmente com o que está sendo tratado em tela.

É pela ficção contida no documentário que vamos concretizando o que está acontecendo ao redor do mundo e com todos nós. Se há algum tempo já vínhamos criticando as redes sociais pela polarização produzida em nossa vida cotidiana, o filme nos permite visualizar o projeto político/econômico/social que está por trás dos algoritmos que manipulam o que vemos nas redes.

$\mathrm{Na}$ realidade brasileira, pudemos perceber uma forte polarização política ocorrendo desde o período que antecedeu o referendo do comércio das armas, realizado no ano de 2005, passando pela segunda campanha à presidência da República de Dilma Rousseff, em 2014, e culminando com o que passou a ocorrer desde a campanha presidencial de Jair Bolsonaro, em 2018.

O documentário "O Dilema das Redes" explicita como a política norte-americana utilizou de fake news nas redes sociais, durante a primeira campanha de Donald Trump, em 2016, para dividir o país entre es adeptes da extrema direita e o restante da população. Para entender a campanha de Trump é preciso primeiramente abordarmos o escândalo da Cambridge Analytica: uma empresa de captação e uso de dados de usuáries de redes sociais.

A empresa em questão coletava informações sobre es usuáries de internet, como suas tendências de compras, suas formas de pensar, o tempo que passavam assistindo publicidades ou mesmo em grupos de discussões e, de posse desses dados, vendiam as informações sem a permissão, claro, dessas pessoas, para empresas e campanhas políticas. Essa prática resultava no uso indevido desses dados, de modo que favoreciam a produção e divulgação de conteúdos que interferiam nas opiniões e 


\section{RevistAleph}

incentivavam votos ou descredibilizavam pessoas e candidatos em processos eleitorais. As notícias criadas tinham por objetivo convencer, desinformar para desestabilizar os processos de participação democráticos.

O uso das fake news na campanha de Donald Trump foi importado pela família Bolsonaro e pelo denominado gabinete de ódio - que hoje está sendo investigado pela Polícia Federal em função da compra de Bots de internet e também pela disseminação do discurso de ódio, o qual faz uso do "comunismo" como vilão para o controle narrativo e político das massas. O documentário, ao expor os caminhos de produção e disseminação de uma política de mentiras, mostra cenas do Brasil durante a campanha presidencial de Bolsonaro.

O documentário evidencia que após coletar os dados des usuáries e de se criar notícias falsas era preciso que alguém ou algo as disseminasse. Nesse contexto, as empresas e campanhas políticas começaram a criar usuáries falses - bots, robô em inglês -, ou compraram pacotes de impulsionamento de notícias. Os bots replicavam nas redes sociais as notícias falsas que eram criadas por perfis reais. Assim, aquelas "informações" proliferavam e pareciam "verdadeiras", em função da grande quantidade de vezes que eram replicadas. São normalmente códigos de programação feitos para interagirem sobre conteúdo específicos e manterem hashtags ("\#") em posições altas no Twitter.

Conforme vamos acompanhando o documentário, vai ficando claro, assim como na narrativa ficcional, como as redes sociais estão sendo usadas para modelar e manipular as pessoas em vários sentidos. Vamos percebendo que elas fazem uso de uma abordagem comportamentalista que interfere nos processos de aprendizagens e na visão de mundo dos indivíduos, influenciando a conscientização crítica dos sujeitos. Observamos que muitos dos membros da família fictícia, principalmente os dois mais jovens, ao serem modelados e manipulados, iam se alienando do que estava acontecendo ao seu redor, tornando-se, ao mesmo tempo, espectadores e produtos das redes sociais, como diz Freire $(1981$, p. 35): 


\section{RevistAleph}

A sociedade alienada não tem consciência de seu próprio existir. [...] O ser alienado não olha para a realidade com critério pessoal, mas com olhos alheios. Por isso vive uma realidade imaginária e não sua própria realidade objetiva. [...] O ser alienado não procura um mundo autêntico [...].

Não podemos deixar de analisar que o desenvolvimento da consciência crítica é condição fundamental para que os seres humanos se comprometam com a própria realidade e, assim, possam transformar o mundo em que vivem, tornando-se sujeitos de sua própria história e não objetos manipuláveis. Ainda, de acordo com Freire (1981, p. 61):

\footnotetext{
Se a vocação ontológica do homem é a de ser sujeito e não objeto, só poderá desenvolvê-la na medida em que, refletindo sobre suas condições espaçostemporais, introduz-se nelas, de maneira crítica. Quanto mais for levado a refletir sobre sua situacionalidade, sobre seu enraizamento espaço-temporal, mais "emergirá" dela conscientemente "carregado" de compromisso com sua realidade, da qual, porque é sujeito, não deve ser simples espectador, mas deve intervir cada vez mais.
}

Contudo, o documentário evidencia que o desenvolvimento da consciência crítica e reflexiva pelos sujeitos não é o objetivo das redes sociais, mas sim a manipulação de suas decisões, partindo da modulação dos comportamentos, induzindo as pessoas a desenvolverem uma forma de aprendizagem que se acomoda às situações de opressão.

\section{A abordagem comportamentalista}

Para a abordagem comportamentalista o desenvolvimento humano é identificado como comportamento observável. O desenvolvimento, para essa teoria, deriva da ação causal exercida pelos objetos exteriores sobre os mecanismos nervosos e cerebrais. Dentro desse enfoque, os sujeitos são seres passivos, de modo que o conhecimento se dá pela absorção do meio; a aprendizagem supõe o treino, a repetição e a memorização; a linguagem é concebida como uma sucessão de estímulos linguísticos que induzem a padrões de comportamentos. 


\section{RevistAleph}

O comportamentalismo ensina como instalar respostas novas e modificar padrões de respostas já existentes, o que o torna, em suma, um paradigma facilmente aplicável à educação. A tal ponto que o próprio Skinner, em seu livro Tecnologia do Ensino (SKINNER, 1972 ${ }^{15}$ ) elaborou propostas bem delineadas para o ambiente escolar, como o "ensino programado" e o emprego de "máquinas de ensinar" verbais (CUNHA, 1988, p. 57).

Assim, as redes sociais vêm investindo nessa abordagem comportamentalista, que acredita que pode instalar respostas novas nes usuáries, modificando padrões já existentes. Segundo a teoria comportamental, o organismo humano é regulado simplesmente por acidentes e contingências naturais. É importante - e nisso consiste o processo da educação ou treinamento social - aumentar as contingências de reforço e sua frequência, utilizando-se de sistemas organizados, pragmáticos, que lançam mão de reforços secundários associados aos naturais, a fim de se obter certos produtos preestabelecidos, com maior ou menor rigor. Leva-se em conta tanto os elementos do ensino como as respostas dos indivíduos analisados em seus componentes comportamentais.

Ao adotar o pressuposto de que todo e qualquer organismo pode ser conduzido a agir mediante condicionamento, o Comportamentalismo tornase facilmente assimilável por aqueles que veem a educação como um arranjo de estímulos ambientais dispostos corretamente para reforçar respostas adequadas (CUNHA, 1988, p. 62-63).

Nessa perspectiva, o ensino é composto por padrões que podem ser modificados por meio de treinamento, segundo objetivos predeterminados. Sobre isso, pretende-se desenvolver comportamento ou habilidades que podem ser mensurados a partir das respostas emitidas, caracterizadas por formas e sequências especificadas.

Verifica-se nesta abordagem que o importante é o resultado final do comportamento. É por meio dele que se identifica a aprendizagem dos sujeitos; assim, dependendo do resultado final, eles poderão ser punidos ou recompensados. Vejamos o que nos diz Skinner (1973, p.21): “Uma pessoa é responsável por seu comportamento,

\footnotetext{
${ }^{15}$ SKINNER, Burrhus Frederic. Tecnologia do Ensino. São Paulo: E. P. U, 1972.
} 


\section{RevistAleph}

não só no sentido de que merece ser admoestada ou punida quando procede mal, mas também no sentido em que merece ser elogiada e admirada em suas realizações".

Influenciades por essa abordagem, as pessoas são elogiadas ou depreciadas por meio de símbolos, como, por exemplo, a curtida, caracterizada pelo polegar para cima $\Omega$, e a não curtida, expressa pelo polegar para baixo $\neg$. Esse sistema acaba influenciando na tomada de decisões de muitos sujeitos que querem, a todo o custo, obter a curtida. O filme fictício presente no documentário demonstra muito bem essa questão quando a filha mais nova tira fotografias suas para postar na rede social. Todavia, antes, ela submete as fotos a um filtro para que fiquem perfeitas. O filtro é um aplicativo que possibilita o manejo de cores e/ou a obtenção de efeitos de luz para a melhoria da imagem.

Entre várias curtidas, a jovem adolescente, no entanto, se prende a um comentário irônico sobre suas orelhas. Com essa informação, o algoritmo do Instagram começa a jogar uma série de publicidades sobre cirurgia plástica e tratamentos estéticos, acentuando o comentário maldoso ou, na gíria das redes, the hate. A junção do cyberbullying com haters tem levado meninas e meninos dessa geração ao suicídio. O cyberbullying é um tipo de assédio virtual. É uma prática que está presente nas tecnologias de informação e comunicação, gerando comportamentos persecutórios, repetidos e agressivos praticados por uma pessoa ou grupo com a intenção de prejudicar alguém. Cada vez mais tem ocorrido em várias sociedades, especialmente entre jovens, e atualmente, legislações e campanhas de sensibilização têm surgido para combatê-lo. Podemos entender melhor ao ler, que:

Cyberbullying é o bullying realizado por meio das tecnologias digitais. Pode ocorrer nas mídias sociais, plataformas de mensagens, plataformas de jogos e celulares. É o comportamento repetido, com intuito de assustar, enfurecer ou envergonhar aqueles que são vítimas. Exemplos incluem: espalhar mentiras ou compartilhar fotos constrangedoras de alguém nas mídias sociais; enviar mensagens ou ameaças que humilham pelas plataformas de mensagens; se passar por outra pessoa e enviar mensagens maldosas aos outros em seu nome (UNICEF, s/d, p. 1). 


\section{RevistAleph}

Assim, percebemos que as redes sociais não controlam somente o comportamento e o tempo, mas influenciam, também, e cada vez mais, no autoconceito (imagem ou ideia que o indivíduo faz de si mesmo), na autoimagem (descrição que a pessoa faz de si, da forma como ela se vê) e na autoestima (a qualidade, o valor que o indivíduo se dá em relação ao que acredita ser) das pessoas. Uma baixa autoestima pode levar o indivíduo a desenvolver uma desvalorização de si mesmo, pode provocar, entre outras questões, insegurança, perfeccionismo, sentimento de inadequação, constantes dúvidas, grande necessidade de aprovação e reconhecimento, baixa capacidade de reagir a frustrações e, por vezes, até depressão (SEPULVEDA, 2003).

"O Dilema das Redes" aborda a quantidade crescente de adolescentes e jovens nos EUA que estão desenvolvendo depressão por causa do Cyberbullying ou por não conseguirem lidar com a falta de aprovação e reconhecimento de suas imagens nas redes sociais. Muitos deles acreditam que não conseguem atingir o alto grau de exigência das aparências físicas presentes em redes, como o Instagram, Facebook, Twitter, etc. E, em função disso, muitos têm cometido suicídio.

\footnotetext{
A taxa de suicídios agora é maior que a de homicídios entre adolescentes e jovens dos Estados Unidos. A mudança ocorreu por volta de 2010 e, desde então, a diferença continua a crescer, segundo relatório do governo norteamericano. Em 2017, o suicídio foi a segunda principal causa de morte, depois de acidentes, para todas as faixas etárias de jovens - 10-14, 15-19 e 20-24 alcançando um recorde naquele ano, de acordo com o Centros de Controle e Prevenção de Doenças. De 2007 a 2017, a taxa de suicídios entre indivíduos entre 10 e 24 anos aumentou $56 \%$ - um ritmo anual de $7 \%$. Oren Miron, da Universidade Harvard, especialista em bioinformática, observou que o maior uso de mídias sociais, ansiedade, depressão e lesões autoinfligidas podem estar contribuindo para o aumento de suicídios de jovens, segundo paper publicado em meados do ano na revista Journal of the American Medical Association (TANZI, 2019, p. 1).
}

No Brasil, o cenário não é muito diferente. Houve um aumento no número de suicídios entre adolescentes e jovens, e alguns dos motivos apresentados dizem respeito à depressão, à baixa tolerância a frustrações e ao alto grau de cobrança em relação à autoimagem, provocada pelas redes sociais. Pesquisas desenvolvidas na Universidade 


\title{
RevistAleph
}

Federal de São Paulo indicam que, entre 2006 e 2015, houve um aumento de 24\% nas taxas de suicídio entre adolescentes e jovens. Por esse motivo, o Ministério da Saúde lançou, em 2017, um Boletim Epidemiológico de Tentativas de Suicídios e Suicídios Consumados no Brasil.

\begin{abstract}
Entender as razões que têm causado sensível aumento nos índices de suicídio entre adolescentes é algo que está posto em debate. "Os números epidemiológicos são significativos e nos direcionam para a busca da compreensão desse fenômeno recente e alarmante", sinaliza Luciana Nogueira Carvalho, especialista em psicologia e psiquiatria para crianças e adolescentes, comentando que, com 30 anos de atendimento clínico, vem observando o aumento no atendimento de pessoas jovens. "Antes era algo raro, agora é constante", indica. A psiquiatra Soraya Hissa ratifica a percepção de uma crescente demanda: só no último fim de semana, foram três atendimentos a adolescentes que tentaram se matar. [...] Para a profissional, "no novo mundo virtual em que estamos todos inseridos, o cenário é de uma adolescência entristecida, solitária, pouco resiliente e com baixa capacidade de suportar a frustração". Opinião compartilhada também pela psicóloga Mariana Tavares, que foi coordenadora das comissões de psicologia clínica e psicologia nas emergências do Conselho Regional de Psicologia de Minas Gerais. "É um fator que pode levar a pouca socialização, perda da percepção do próprio corpo, das relações fora da rede. Há uma lacuna, uma falta da experiência vivida", diz, completando que é preciso recriar ambientes de socialização (BESSAS, 2019, s/p).
\end{abstract}

Nossas análises nos levam a inferir que as redes sociais, a partir de uma abordagem comportamentalista, têm influenciado de maneira negativa a aprendizagem feminina, no que diz respeito ao autoconceito, a autoestima e à autoimagem. Imersas e reproduzindo uma cultura machista, essas redes objetificam a mulher, levando adolescentes e jovens a um alto grau de cobrança de suas imagens, o que tem gerado depressão e suicídio.

\begin{abstract}
A hipersexualização do corpo feminino está tão enraizada na sociedade que, consequentemente, não construímos o hábito de refletir e/ou questionar atitudes em que o corpo da mulher é estampado nas propagandas publicitárias utilizadas para promover produtos, perfumes, bebidas, carros, times de futebol, escolas de samba, concursos de beleza, etc.. Logo, precisamos ficar atentas para perceber que a objetificação do corpo feminino está em nossa cultura cotidianamente e enraizada em todos os meios sociais e, sem refletir sobre os aspectos que alimentam a cultura machista, corremos o risco de reproduzir padrões estabelecidos pelo gênero masculino, onde o corpo feminino torna-se um mero objeto de desejo e consumo,
\end{abstract}




\section{RevistAleph}

desconsiderando o potencial intelectual e psicológico das mulheres. A banalização da sexualidade e a hipersexualização do corpo feminino nos meios de comunicação, videoclipes e publicidade caminham junto com a tentativa de reforçar modelos de feminilidade que separam as mulheres entre as "recatadas" e as "vadias" - todas disponíveis para os homens, independente do grupo a que possam pertencer (COSTA, 2018, p. 1).

O documentário permite que as mulheres visualizem a hipersexualização e objetificação que a mídia produz dos corpos femininos, e media o desenvolvimento de um pensamento crítico em relação às redes sociais, possibilitando que saiam de uma postura de alienação e se distanciem da cultura capitalista/machista que se impõe e que lucra com o uso de suas imagens.

A teórica da comunicação Shoshana Zuboff (2020) começou a olhar para o fenômeno da internet e das redes sociais e percebeu uma mudança sistêmica no modus operandi do capitalismo. Ela afirma que, assim como o fordismo alterou as relações sociais, a invenção e o uso das redes sociais mudaram no mesmo nível, ou mais, as relações. Segundo a autora, as propagandas feitas pelo Google e emuladas por Facebook, Youtube e Twitter, fundaram a prática de vigiar e obter dados que possibilitam a criação e utilização de novas publicidades customizadas aos interesses de cada grupo. A esse novo momento Zuboff (2020) chamou de Capitalismo de Vigilância. Ou seja, ao vigiarem nossos comportamentos on-line, as marcas que financiam as novas mídias têm acesso, por meio de algoritmos, aos nossos gostos, e com isso, conseguem interferir em nossos hábitos de consumo e comportamentos.

Se unirmos a ideia de capitalismo de vigilância ao conceito de capitalismo tardio, muito explorado por autores como Adorno (2009) e Lukács (2014) - apesar de algumas diferenças de análise acerca de como o capitalismo tardio afeta os indivíduos perceberemos que o fim da Guerra Fria transformou o capitalismo e gerou a globalização, as multinacionais e o consumo de massa. A conclusão dessa nova fase seria que o incentivo ao ultra consumo levaria a um esgotamento dos recursos naturais. É importante aqui constar que a cultura globalizada e os padrões de comportamento de consumidores foram diretamente alterados pelas redes sociais, seja na construção dos 


\section{RevistAleph}

estereótipos de nichos de consumo - hipster, intelectual, guetos, moda urbana - ou na entrada de marcas nesses grupos. $\mathrm{Na}$ internet, influenciadores de comportamento incrementam essa dinâmica: são indivíduos que utilizam as redes sociais para darem todo tipo de dica, e com isso, conseguem cooptar usuáries. Diante do alcance de alguns, marcas aproveitam esse potencial midiático para darem projeção aos seus produtos, associando seus conteúdos à página/ perfil do influenciader.

Neste ponto temos algumas reflexões que precisam ser explicitadas. Primeiramente, entendemos que os avanços tecnológicos trazem elementos negativos e positivos para a sociedade. Afinal, as tecnologias ganham a função que damos a elas e não seria diferente com as redes sociais. O número de grupos de apoio e de movimentos sociais, bem como a aproximação científica entre nós, são pontos que consideramos positivos. Observamos, com a crise do coronavírus ${ }^{16}$, das quarentenas ${ }^{17}$ e do isolamento social $^{18}$, as conexões pela internet estão sendo ampliadas. Vemos cientistas do mundo inteiro trabalhando juntes e enviando dados pelas redes sociais sobre os resultados de suas pesquisas, assim como sobre protocolos de proteção necessários para serem

${ }^{16}$ Os coronavírus são uma grande família de vírus comuns em muitas espécies diferentes de animais, incluindo camelos, gado, gatos e morcegos. Raramente, os coronavírus que infectam animais podem infectar pessoas, como exemplo do MERS-CoV e SARS-CoV. Recentemente, em dezembro de 2019, houve a transmissão de um novo coronavírus (SARS-CoV-2), o qual foi identificado em Wuhan na China e causou a COVID-19, sendo em seguida disseminado e transmitido de pessoa a pessoa. A COVID-19 é uma doença causada pelo coronavírus, denominado SARS-CoV-2, que apresenta um espectro clínico, variando de infecções assintomáticas a quadros graves. De acordo com a Organização Mundial de Saúde, a maioria (cerca de 80\%) dos pacientes com COVID-19 podem ser assintomáticos ou oligossintomáticos (poucos sintomas), e aproximadamente $20 \%$ dos casos detectados requer atendimento hospitalar por apresentarem dificuldade respiratória, dos quais aproximadamente $5 \%$ podem necessitar de suporte ventilatório (mais informações, consultar referências bibliográficas).

${ }^{17}$ Em questões de saúde pública, o termo quarentena é utilizado para definir o isolamento de certas pessoas, lugares e animais que podem acarretar perigo de infecção. $O$ período de quarentena é relativo e depende do tempo necessário para proteção contra a propagação de uma determinada doença. Isso significa que o tempo de quarentena pode variar e nem sempre compreende o período de 40 dias, podendo ser menor ou maior, de acordo com o período de incubação de uma doença. Se a pessoa esteve em contato com alguém que tem o vírus deve ficar em quarentena aguardando para ver se tem sintomas. (mais informações, consultar referências bibliográficas).

${ }^{18} \mathrm{O}$ termo isolamento social é utilizado para definir o estado de uma coisa ou uma pessoa isolada, privada do contato social. Também pode referir-se a um local, um edifício ou parte deste que é destinada à segregação e ao tratamento de pacientes com doenças contagiosas (mais informações, consultar referências bibliográficas). 


\title{
RevistAleph
}

usados por todas as populações. Mulheres se unindo em grupos on-line para criarem símbolos de proteção contra as violências domésticas. Nesse sentido, é importante mencionar que, durante as primeiras semanas do isolamento social, vivenciou-se um aumento da violência contra a mulher no mundo todo.

\begin{abstract}
A necessidade do isolamento social decorrente da pandemia do COVID-19 trouxe muitos reflexos para a vida de todas as pessoas, positivos para algumas e negativos para outras. As mulheres são um grupo que têm sentido os efeitos negativos, dado o aumento drástico da violência doméstica e familiar. Isso se deve a uma série de fatores, como a perda ou diminuição da renda familiar em razão do desemprego, suspensão das atividades de trabalho, sobrecarga das tarefas domésticas, incluindo o cuidado dos filhos fora da escola, aumento do consumo de bebidas alcoólicas, isolamento da vítima de seus amigos e familiares, e outras situações que aumentam o tensionamento nas relações domésticas. Por essas razões, esse aumento não ocorreu exclusivamente no Brasil. A violência doméstica também cresceu significativamente em outros países que foram duramente afetados pela pandemia (POLITIZE, 2020, s/p).
\end{abstract}

Na quarentena, por causa do aumento da violência doméstica contra a mulher, a internet está sendo usada para denúncia virtual. Em alguns estados brasileiros, estão sendo feitos boletins de ocorrência on-line e solicitação de medidas protetivas. Medidas de solidariedade também foram desenvolvidas pelas redes sociais, tais como a campanha vermelha, o desenvolvimento do aplicativo botão do pânico, entre outras.

A Campanha Sinal Vermelho, que foi lançada pelo Conselho Nacional de Justiça em parceria com a Associação dos Magistrados Brasileiros, visa auxiliar a vítima de violência doméstica e familiar a denunciar a agressão. Basta se dirigir a uma farmácia e mostrar um " $X$ " vermelho na palma da mão a algum atendente, que identificará o sinal e acionará a Polícia. [...] O Botão do pânico é um dispositivo eletrônico - com GPS e até gravador de áudio que emite alertas caso a mulher se sinta ameaçada pelo agressor. Alguns estados e prefeituras desenvolveram aplicativos para facilitar o processo. Iniciada no Espírito Santo, hoje a medida se espalhou por vários estados, englobando parcerias do Judiciário com o Executivo. Funciona assim: após a formalização da medida protetiva, a vítima pode escolher se usará o dispositivo. A partir do acionamento pela mulher, as forças de segurança pública identificam o local e podem acionar viaturas para o local (POLITIZE, 2020, s/p). 


\section{RevistAleph}

Contudo, apesar dos aspectos positivos das redes sociais serem extremamente importantes, não podemos deixar os negativos ofuscados. Pelo contrário, é na luta pelo melhor uso possível das novas ferramentas culturais que reside toda ideia de construção instituinte em nossa sociedade. Tomarmos a defesa de que o uso das ferramentas criadas, usadas e disponibilizadas pela globalização, visando a inclusão e não a segregação, deve ser nossa missão. Um conjunto de teóricos da comunicação discute os efeitos da globalização no mundo, e a eles foi dado o nome de movimento antiglobalização. Trazemos para dialogar aqui conosco Muniz Sodré (2004) e Naomi Klein (2009).

O primeiro nos alertou sobre o perigo da globalização e de como a tentativa de achar uma linguagem universal é um projeto capitalista para controlar percepções e achatar culturas e línguas locais. Ele vinha alertando que tentar dar nome ou significado a globalização é completamente impossível. Isso porque o ideário capitalista de globalização funciona de forma regional, criando um imaginário de consumo para construção de nichos. Ou seja, se definem padrões estéticos, literários, narrativos que são impostos pelo mercado a culturas locais. Na relação entre padrão imposto e cultura local nasce algo que beneficia o mercado, mas que altera o comportamento regional. A segunda referência, a jornalista e teórica Naomi Klein (2009), faz uma análise sistêmica de como o capitalismo se apropriou da globalização. Se de um lado Sodré avalia os impactos do mundo globalizado nas sociedades regionais, Klein se preocupa em identificar o uso mercadológico das empresas nesse cenário global. Segundo a autora, as empresas se apropriam de guerras, desastres naturais e do choque de culturas para avançar suas agendas que empobrecem as populações enquanto enriquecem um grupo pequeno de capitalistas. A autora afirma que as medidas criadas pelos grupos econômicos hegemônicos causam uma reação e esta é duramente apagada pelas forças policiais.

Es autores abordam as mídias e as novas redes como importantes no processo de apagamento. Em primeiro lugar porque a dinâmica da informação virou sinônimo de 


\section{RevistAleph}

velocidade, pois o furo jornalístico passou a ser mais importante do que a confirmação dos dados. Podemos observar que as mídias precisam sistematicamente escrever diversas retratações, o que pode ser um motivo do atual questionamento das mídias tradicionais. O segundo aspecto, importante de se destacar, é o fato de que quando a velocidade passa a ser o motor de credibilidade de uma notícia, temos o cenário perfeito para o estabelecimento das empresas de fake news. O foco está na velocidade de publicação e no poder de convencimento. Es usuáries passam por um processo no qual seus comportamentos, seus desejos, suas prioridades e suas visões de mundo vão sendo deslocados pelos interesses do capital.

\section{Algumas reflexões finais}

Em um determinado momento o documentário mostra um dos filhos da família fictícia na escola. Ele está em sala de aula, mas sua atenção está voltada para o seu celular, vendo as mensagens, imagens, notícias e propagandas que estão sendo postadas. O professor, por sua vez, não percebe sua desconexão com a aula e continua sua explanação como se nada estivesse acontecendo.

O documentário faz uma leitura trágica da rede da internet. Mas como subverter esse estado de coisas? A escola pode ser um espaço para romper com essa dominação?

Em pesquisa de doutorado, elaborada em 2005, a professora Edméa Santos já apontava para o potencial das redes on-line nos processos de ensinar e aprender de estudantes e docentes, assim como para a pesquisa-formação.

\footnotetext{
A tese desenvolve a teoria e a prática da educação online como um evento da cibercultura e não simplesmente uma evolução das convencionais práticas de educação a distância. A cibercultura é o movimento sociotécnico-cultural que gesta suas práticas a partir da convergência tecnológica da informática com as telecomunicações que faz emergir uma pluralidade de interfaces síncronas e assíncronas de comunicação e uma multiplicidade de novas mídias e linguagens que vêm potencializando novas formas de sociabilidade e, com isso, novos processos educacionais, formativos e de aprendizagem baseados nos conceitos de interatividade e hipertextualidade (p. 10).
} 


\section{RevistAleph}

As novas tecnologias digitais permitem que as escolas possam tecer currículos que garantam novas práticas pedagógicas emancipatórias, em que a interação professor/aluno/conhecimento seja incorporada, se distanciando de práticas engessadas que se preocupam, muitas vezes, com conteúdos distantes des alunes e que os levam cada vez mais a se desinteressarem do que é trabalhado na escola, como o filho da família fictícia do documentário.

Acreditamos na importância do papel da escola como espaço dialógico e crítico para o que vem sendo exposto na internet. É necessário que os currículos praticados nas instituições escolares dialoguem sobre outras dimensões de comunicação, para que novas ações pedagógicas e construções de conhecimentos emancipatórios sejam tecidas nas salas de aulas. Assim, como Santos (2005, p. 25), defendemos a importância de que os currículos sejam praticados em redes.

\footnotetext{
Pensar o currículo em rede é conceber uma teia de conexões na qual o professor pode estar ou não no centro, os estudantes podem tomar a cena criando e cocriando situações de aprendizagens, e conteúdos disponibilizados e interfaces (ferramentas) podem ganhar destaque no processo. $\mathrm{O}$ que importa nessa complexa rede de relações é a garantia da produção de sentidos, da autoria dos sujeitos/coletivos. O conhecimento deve ser concebido como fios que vão sendo puxados e tecidos criando novas significações, num processo em que alguns vão conectar-se a novos, outros serão refutados (..), até que novos fios sejam tecidos a qualquer tempo/espaço, na grande rede que é o próprio mundo.
}

Assim, apostamos em práticas curriculares tecidas em rede que instituam reflexões que potencializem atitudes de enfrentamento às situações opressoras a que são expostos os jovens em suas imersões nas navegações pelas redes digitais.

\section{Referências}

ADORNO, Theodor Ludwig Wiesengrund. Dialética negativa. Tradução de M. A. Casanova. Revisão de E. S. Neves Silva. Rio de Janeiro: Zahar, 2009. 


\section{RevistAleph}

BESSAS, Alex. Índice de suicídio entre adolescentes cresce $\mathbf{2 4 \%}$ em nove anos. Disponível em: https://www.otempo.com.br/interessa/indice-de-suicidio-entre-adolescentes-cresce-24-emnove-anos-1.2173731. 2019. Acesso em: 10/10/2020.

COSTA, Ana Kerlly Souza da. Hipersexualizaçao frente ao empoderamento: a objetificação do corpo feminino evidenciada. Disponível em:

https://7seminario.furg.br/images/arquivo/338.pdf. Acesso em: 10/10/2020.

CUNHA, Marcus Vinicius. A psicologia na educação: dos paradigmas científicos às finalidades educacionais. Cadernos Espinosanos. São Paulo, vol. 4, n. 2, jul./dez. 1988.

FARMACÊUTICO DIGITAL. O que é quarentena? O que é isolamento?. Disponível em: https://farmaceuticodigital.com/2020/03/o-que-e-quarentena.html. Acesso em: 14/10/2020.

FREIRE, Paulo. Educação e mudança. São Paulo: Paz e Terra, 1981.

KLEIN, Naomi. A doutrina do choque. São Paulo: SmartBook, 2009.

LUKÁCS, Gyõrgy. Para uma ontologia do ser social. V. 2, Boitempo: São Paulo, 2014.

MINISTÉRIO DA SAÚDE. O que é COVID-19. Disponível em:

https://coronavirus.saude.gov.br/sobre-a-doenca\#como-se-proteger. Acesso em: 14/10/2020.

POLITIZE. Violência doméstica no Brasil: desafios do isolamento. Disponível em: https://www.politize.com.br/violencia-domestica-no-brasil. Acesso em: 11 de outubro de 2020.

UNICEF. Cyberbullying: o que é e como pará-lo - 10 coisas que adolescentes querem saber sobre cyberbullying. Disponível em: https://www.unicef.org/brazil/cyberbullying-o-que-eh-ecomo-para-lo. Acesso em: 09/10/2020.

SANTOS, Edméa Oliveira dos. Educação On-line: cibercultura e pesquisa-formação na prática docente. Programa de Pós-Graduação em Educação. 351 p. Tese (Doutorado em Educação) Faculdade de Educação, Universidade Federal da Bahia, Salvador, 2005.

SEPULVEDA, Denize. Avaliação, formação do/a professor/a e fracasso escolar: uma relação de complexidade presente no cotidiano da escola. Programa de Pós-Graduação em Educação. 156 p. Dissertação (Mestrado em Educação) - Faculdade de Educação, Universidade Federal Fluminense, Niterói, 2003.

SKINNER, Burrhus Frederic. O mito da liberdade. Rio de Janeiro: Bloch, 1973.

SODRÉ, Muniz. O globalismo como neobarbárie. In: MORAES, Dênis (org.). Por uma outra comunicação. Rio de Janeiro: Record, 2004.

TANZI, Alexandre. Suicídio aumenta entre adolescentes e jovens nos EUA. Disponível em: https://economia.uol.com.br/noticias/bloomberg/2019/10/17/suicidio-aumenta- 


\section{RevistAleph}

entre-adolescens-e-jovens-nos-eua.htm. Acesso em: 10/10/2020.

YORK, Sara Wagner. / GONÇALVES Junior. Sara Wagner Pimenta. TIA, VOCÊ É HOMEM?

Trans da/na educação: Des(a)fiando e ocupando os \&quot;cistemas\&quot;. Programa de PósGraduação em Educação. 190 p. Dissertação (Mestrado em Educação) - Faculdade de Educação, Universidade do Estado do Rio de Janeiro, Rio de Janeiro, 2020.

ZUBOFF, Shoshana. Facebook, Google e uma era das trevas do capitalismo de vigilância. 25 de janeiro de 2019. Disponível em: https://www.ft.com/content/7fafec06-1ea2-11e9-b12646fc3ad87c65. Acesso em: 25/04/2021.

Data do envio: $25 / 04 / 2021$

Data do aceite: $16 / 05 / 2021$ 